\title{
The Role of Education in Strengthening the Resilience of Pastoral Systems to Climate Change Adaptation
}

\author{
Altanbagana Myagmarsuren ${ }^{1, *}$, Mungunchimeg Batkhuyag ${ }^{1}$ \\ ${ }^{1}$ Institute of Geography and Geoecology, Mongolian Academy of Sciences, Ulaanbaatar, Mongolia \\ "Corresponding author. Email: Altanbaganam@mas.ac.mn
}

\begin{abstract}
The pastoral system in Mongolia is one of the most vulnerable sectors to the adverse effects of ongoing climate change because of its climatic condition, geographical location, and community lifestyle. Therefore, building a resilient socio-ecological system by reducing the sector's vulnerability and increasing its resilience is an important issue not only at the research level but also at the policy level. Study of Mongolia's pastoralism from a point of view of the integrated system of "herder-pastoral ecosystem-livestock" is important for strengthening the long-term resilience and adaptive capacity to climate change. In particular, education, a key component of the vulnerability and adaptive capacity, is the main factor contributing to poverty in a way that affects people's livelihoods. From a systemic point of view, as poverty increases, vulnerability increases, and capacity for resilience decreases. Therefore, this study explains the role of education in enhancing the resilience of the livestock sector and pastoral systems. Within the framework of the research, the relationship between resilience, adaptive capacity, and vulnerability is explained in theory, and the livestock sector is viewed in the context of complex socio-ecological systems.
\end{abstract}

Keywords: Pastoral systems, resilience, education, adaptive capacity, climate change

\section{INTRODUCTION}

In recent years, mitigating and adapting to the adverse effects of climate change caused by human activities have become a relevant issue at global, national, regional, and local levels $[1 ; 2]$. As Mongolia is located in a region of arid and semi-arid ecosystems, with nomadic culture and a predominance of pastoralism, which is vulnerable to the climate change, adapting to it and strengthening its resilience are critical issues [3].

Adverse events caused by climate change, such as drought and dzud, increase livestock mortality and lead to internal migration from rural to urban due to poverty caused by loss of livestock. This is due to the lack of adaptive capacity of the livestock sector at the national level. On the other hand, pastoral livestock in Mongolia is a traditional and basic economic sector of the nation's employment, and as of 2019, it accounted for 10.9 percent of GDP and 25.3 percent of the total labor force [4]. In terms of settlement patterns, rural poverty $(30.8 \%)$ is higher than urban poverty $(27.2 \%)$. Urban and rural populations vary in their ability to cope with the risks of climate change and their ability to adapt, depending on the type of business and living conditions. The lower the income the herders gain in the livestock sector, the more vulnerable they are to climate change and the less able they are to adapt and cope with any risks.

Education is one of the key mechanisms to reduce poverty and improve living standards. An uneducated person is employed in a job that does not require professional skills, or in a low-paying job. However, adapting to climate change requires knowledge, skills, and management from herders. According to the analysis of the relationship between education level and poverty, the higher the level of education of the head of the household, the less likely the household is to fall into poverty. The statistics of 2019 indicated that out of 285.4 thousand herders, only $10.1 \%$ had technical, vocational or higher 
education, and the remaining 90 percent had secondary, primary education or no education [4].

In this paper, we describe the role of education to reduce the vulnerability of the livestock systems to climate change and strengthen its capacity for adaptation and resilience. The outputs of the study can be used to support the adaptation policy and strategies to prioritize key issues.

\section{THE SYSTEMIC PERSPECTIVE OF RESILIENCE, ADAPTIVE CAPACITY, AND VULNERABILITY TO CLIMATE CHANGE}

Scholars have argued that integration of societal (human) and ecological (biophysical) systems have to be investigated as an integrated socio-ecological system (SES) in the field of climate change $[5 ; 6]$. As the dynamic interplay between the two systems has captured the attention of scholars and environmental policy-makers in recent decades, linkages of the vulnerability, resilience, and adaptive capacity of those systems are relevant to understand the ways of coping with the harmful effects of climate change.

Vulnerability is a broad concept used in different fields. However, vulnerability can be explained in the research of climate change-related risk, hazard, and disaster as the degree to which human and environmental systems are likely to experience harm due to a perturbation or stress $[7 ; 8]$. In other words, vulnerability refers to a certain system's susceptibility to harm in climate change. Resilience is opposite to the vulnerability. To clarify, resilience describes the ability of a social or ecological system to absorb disturbances, while retaining the same basic ways of functioning, and a capacity to adapt to stress and change [9]. The adaptive capacity indicates the ability of the system to become adapted to a certain range of environmental contingencies [5].

In recent studies of climate change, adaptive capacity has been defined as the ability of natural or human systems to adjust to actual or expected climatic stimuli or their effects [7]. From the systemic perspective, the concepts of vulnerability, resilience, and adaptive capacity are related to each other [5]. For instance, vulnerability and resilience are the two sides of the same coin [10]. It means that an increase in vulnerability results in a decrease in resilience. Resilience focuses on the ability of the system to return to the original system, while vulnerability considers the exposure, sensitivity, and capacity of response to the effects of climate change.
Bene [11], Berman [12], Engle [13] claim that adaptive capacity is considered as buffering between resilience and vulnerability. According to them, adaptive capacity can be increased when the vulnerability decreases, and it results in increasing resilience. To sum up, the literature argued that vulnerability, resilience, and adaptive capacity are interlinked in explaining the effects of climate change.

\section{RESILIENCE CAPACITY OF PASTORAL SYSTEMS}

Pastoralism is a basic lifestyle of nomadic culture. Nomadic pastoralism is a "herder-pastoral ecosystemlivestock" trilateral connection, which is a "pastoral social-ecological system". They are linked to sustain each other and contain adaptation and resilience capacity at a certain level. Mongolia's nomadic pastoral culture has been a mechanism for adapting to the fluctuations of arid and semi-arid ecosystems [14; 15]. For instance, pasture migration is a form of adaptation that allows the protection, use, and renewal of pasture ecosystems. Pastoralism plays an important role in socio-economic development and becomes one of the main economic sectors. From the systemic perspective, nomadic pastoralism presents the interconnection between society (herders), nature (pasture), and economy (livestock) in the sustainable development field, and can be considered as interdisciplinary, trans-disciplinary, and multidisciplinary research (See Figure 1).

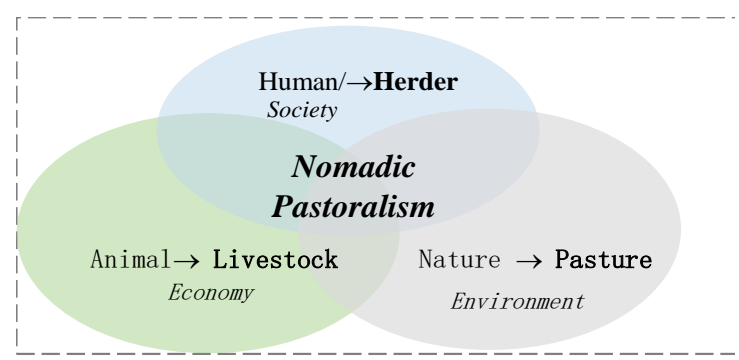

Figure 1. Scheme of Nomadic pastoralism [16]

From the point of view of pastoral livestock as an integrated socio-ecological system, the resilience of pastoral livestock systems can be explained as follows:

1) The resilience of the rangeland is the ability of a pastureland ecosystem to recover from the harmful effects of climate variables, such as drought and dzud, and human activities, such as overgrazing. Traditional knowledge and awareness of herders' pasture management are positively related to this capacity. 


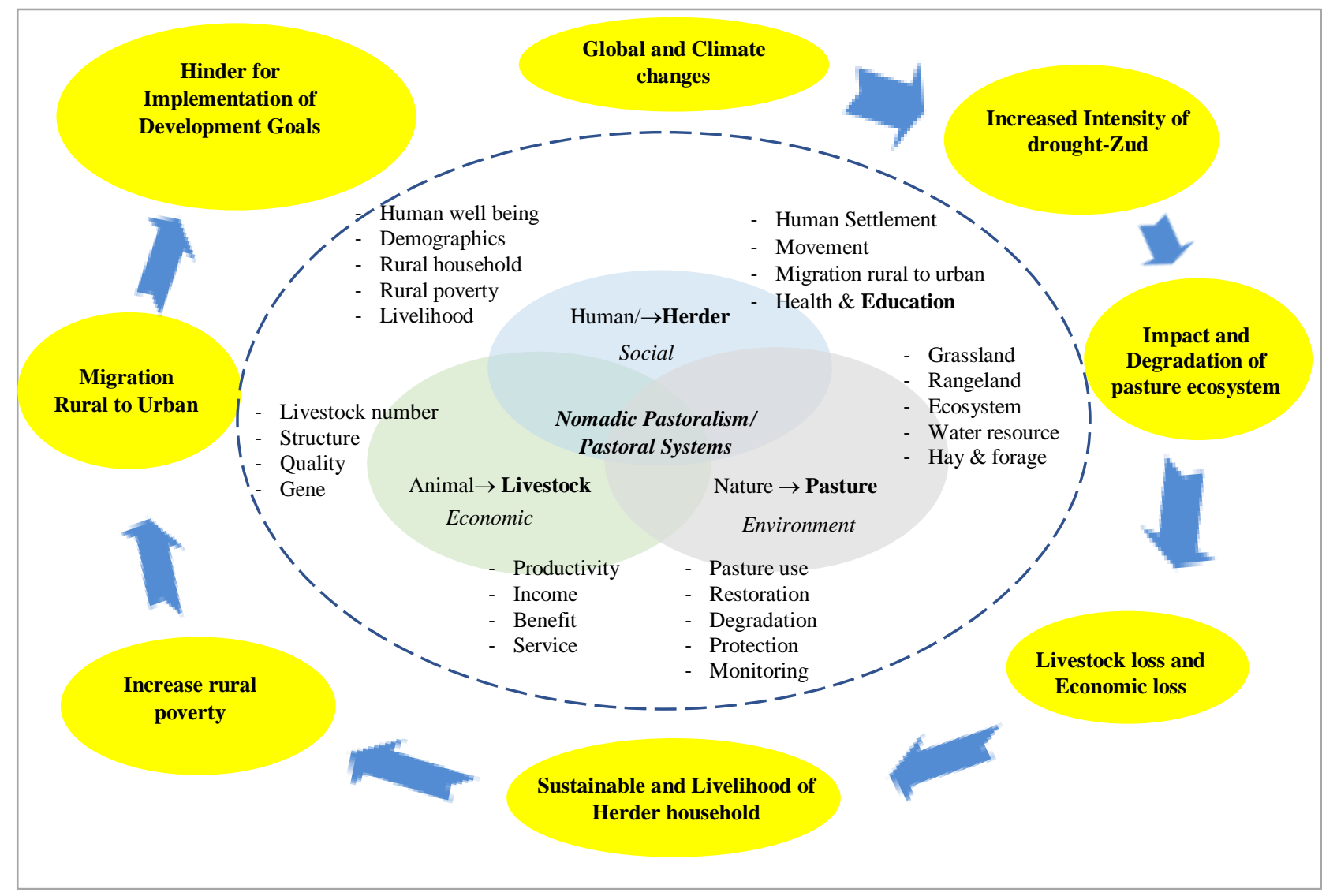

Figure 2. Chain of interlinkage between pastoral systems and the impact of climate change

2) The resilience of a livestock system is described by its ability to use a complex landscape and overcome climate variables, drought, and dzud, at low risk, and can be developed based on the resilience of pasture ecosystems when livestock numbers are at risk.

3) Herders' resilience can be supported by traditional knowledge, education, and living standards. However, in the current context, in addition to the traditional herding knowledge, it is important to use modern knowledge, innovation, and new technologies to increase the resilient capacity (Figure 2).

\section{THE ROLE OF EDUCATION IN STRENGTHENING THE RESILIENCE OF THE PASTORAL LIVESTOCK SYSTEM}

From the systemic perspective of resilience, vulnerability, and adaptive capacity, enhancing the resilience of the pastoral livestock system to respond to the adverse impacts from climate change mean decreasing vulnerability and increasing adaptive capacity. Yet, there are a number of indicators influencing the vulnerability and adaptive capacity, and education is recognized as a powerful tool in enabling less vulnerability and effective adaptation at all levels, particularly at a local community level [1; 17].

The role of education in adaptation and resilience has been studied in some developing countries. For instance, Paavola [18] examined that education is key a component of building long-term adaptation and resilience to climate change impacts in Tanzania. Moreover, Eakin [19] determined the importance of wealth and education to enhance adaptive capacity in a case study of Mexico. These studies demonstrated that adaptation strategies with the long-lasting resilience aim should include education as the main component. Because, receiving high-quality or highlevel education, and climate literacy support not only disaster preparedness before extreme events, but also enhance post-disaster intervention at a community level.

Access and quality of education vary among herder community. We would argue that the lower the level of education or lack of education, the greater 
the risk of falling into poverty, which can lead to vulnerability and reduce the adaptive capacity and resilience capacity. We can see this relation from the statistics shown in Table 1.

Moreover, it is seen from Table 1, the lower the level of education, the higher the poverty rate. 285.4 thousand herders are working in the livestock sector of Mongolia, of which $23.2 \%$ have primary education, $39.9 \%$ have lower secondary education, $23.1 \%$ have upper secondary education, $3.7 \%$ have higher education, $6.4 \%$ have vocational education, while $3.7 \%$ have no education (see Table 2). It means that only $10 \%$ of the herders (vocational education (6.4\%) and higher education (3.7\%)) have a profession, which provides good income and adaptive capacity to climate change.

Table 1. Poverty and education, by education of the head of the household [20]

\begin{tabular}{|l|l|l|l|l|l|}
\hline & \multicolumn{1}{|c|}{$\begin{array}{c}\text { The national } \\
\text { average }\end{array}$} & $\begin{array}{c}\text { No } \\
\text { education }\end{array}$ & $\begin{array}{c}\text { Primary } \\
\text { education }\end{array}$ & $\begin{array}{c}\text { Secondary } \\
\text { education }\end{array}$ & $\begin{array}{c}\text { Higher } \\
\text { education }\end{array}$ \\
\hline Poverty rate & $35.2,(0.8)$ & $58.0,(2.8)$ & $51.5,(1.7)$ & $48.1,(1.4)$ & $9.5,(1.1)$ \\
\hline Poverty gap & $10.1,(0.3)$ & $19.8,(1.4)$ & $16.0,(0.7)$ & $14.1,(0.5)$ & $2.1,(0.3)$ \\
\hline $\begin{array}{l}\text { The severity of } \\
\text { poverty }\end{array}$ & $4.0,(0.2)$ & $8.9,(0.9)$ & $6.7,(0.4)$ & $5.6,(0.3)$ & $0.6,(0.1)$ \\
\hline
\end{tabular}

Table 2. Education level of herders, by 2018 [21]

\begin{tabular}{|c|c|c|c|c|c|c|}
\hline \multirow{3}{*}{$\begin{array}{c}\text { Total } \\
\text { number of } \\
\text { herders } \\
\text { /thousands/ }\end{array}$} & \multicolumn{6}{|c|}{ Education level } \\
\hline & \multirow{2}{*}{$\begin{array}{c}\text { No } \\
\text { education }\end{array}$} & \multirow{2}{*}{$\begin{array}{l}\text { Primary } \\
\text { education }\end{array}$} & \multicolumn{2}{|c|}{ Secondary education } & \multirow{2}{*}{$\begin{array}{l}\text { Vocational } \\
\text { and technical } \\
\text { education }\end{array}$} & \multirow{2}{*}{$\begin{array}{c}\text { Higher education } \\
\text { (graduated colleges and } \\
\text { universities) }\end{array}$} \\
\hline & & & Lower & Upper & & \\
\hline $285.4(100 \%)$ & $\begin{array}{c}10.5 \\
(3.7 \%)\end{array}$ & $\begin{array}{c}66.2 \\
(23.2 \%)\end{array}$ & $\begin{array}{c}113.8 \\
(39.9 \%)\end{array}$ & $\begin{array}{c}65.9 \\
(23.1 \%)\end{array}$ & $\begin{array}{c}18.2 \\
(6.4 \%)\end{array}$ & $\begin{array}{c}10.5 \\
(3.7 \%)\end{array}$ \\
\hline
\end{tabular}

Education can be broadly classified as formal and informal [22]. Formal education is processed based on a strict curriculum and delivered by the state or private schools, colleges, or universities, while informal education more refers to traditional values and knowledge. In the Mongolian case, informal education or traditional herding ways have been handed down from generation to generation among herders. However, the relatively low level of formal education which is gained in attending the schools has weakened the resilience of the integrated system of "herders- pasture-livestock" by increasing their vulnerability and reducing their adaptive capacity to adverse impacts from climate change. Therefore, education needs to be prioritized in policy measures and strategies to mitigate the effects of ongoing climate change and to improve the long-term resilience of the livestock sector and pastoral systems [23].

\section{DISCUSSION}

Mongolia's nomadic culture has existed for hundreds of years, and the pastoral socio-ecological system (herder-animal-pasture) has adapted to any changes in a mutually supportive way $[10 ; 1]$. However, the adverse effects of climate change, which has intensified in recent years, increase the vulnerability of the socio-ecological systems of pastoral livestock. Therefore, increasing the adaptive capacity and resilience of the pastoral system to climate change is a pressing issue for researchers and policymakers. Vulnerability, adaptive capacity, and resilience are interrelated systemic concepts. Considering the problem from this perspective can improve the long-term sustainability of the system's ability to adapt and recover from climate change.

From the point of view of the integrated socioecological system of pastoral livestock, increasing the capacity and resources of rural herders to adapt to climate change is important to strengthen the resilience of the integrated system (herder-animalpasture) as a whole. One of the factors leading to vulnerability for rural herders is poverty, and poverty and education are inversely related. As the level of education increases, the level of poverty decreases, and the capacity for adaptation and recovery increases.

Therefore, herders' education needs to be prioritized in order to strengthen the resilience and adaptive capacity of the pastoral system to climate change. In other words, supporting herder education can be a long-term, sustainable strategy for adapting to the adverse effects of climate change. 


\section{CONCLUSIONS}

The livestock sector accounts for 10.9 percent of GDP and 25.3 percent of the total labor force. A total of 285.4 thousand herders are employed in the livestock sector, of which 63 percent have lower secondary education.

On the other hand, the livestock sector is one of the most vulnerable sectors to climate change. However, the capacity of the livestock sector to adapt to climate change has not been strengthened at the national level.

From the research point of view, the livestock sector is a system concept of "herder-pasturelivestock" with pastoral socio-ecological interaction and consists of many external and internal variables that affect the system (Figure 2). Many variables in this interactive system have different natures and patterns and can lead to resilience, adaptive capacity, or vulnerability to climate change.

The results of this study note that herders' education, one of the variables that make up the "herder-pasture-livestock" interaction system, is a key variable for the long-term, sustainable resilience of the system. For instance, at a time when the majority of herders working in the livestock sector, or 63 percent, have lower secondary education, it is not possible to strengthen the "herder-pasture-livestock" system's ability to adapt to climate change without education.

Therefore, the gradual support of knowledge and education of herders to adapt to climate change is one of the main factors to ensure the sustainable development of the livestock sector.

\section{ACKNOWLEDGMENTS}

The researchers sincerely thank the Institute of Geography and Geoecology, Mongolian Academy of Sciences and colleagues for supporting the research work.

\section{REFERENCES}

[1] IPCC, "The Fifth Assessment Report (AR5)," 2014.

[2] World Bank, "Climate Change Action Plan 2021-2025,” 2021.

[3] T. Chuluun, M. Altanbagana and D. Ojima, "Vulnerability and Resilience of the Mongolian Pastoral Social-Ecological Systems to Multiple Stressors," in Vulnerability of Land Systems in Asia, 2014.
[4] NSO, "Mongolian Statistical Year Book-2019," Ulaanbaatar, 2019.

[5] G. C. Gallopín, "Linkages between vulnerability, resilience, and adaptive capacity," Global Environmental Change, vol. 16, pp. 293-303, 2006.

DOI: https://doi.org/10.1016/j.gloenvcha.2006.02.004

[6] J. Berkes, C. Folke and J. Colding, Navigating Social-Ecological Systems Building Resilience For Complexity And Change, Cambridge University Press, 2003.

[7] IPCC, “TAR Climate Change 2001,” 2001.

[8] L. Luers and D. B. Lobell, "A method for quantifying vulnerability, applied to the agricultural system of the Yaqui Valley, Mexico," Global Environmental Change, no. 13, pp. 255-67, 2003. DOI: https://doi.org/10.1016/S0959-3780(03)00054-2

[9] W. N. Adger, "Social and ecological resilience: are they related?," Progress in Human Geography, vol. 24, no. 3, pp. 347-64, 2000. DOI: https://doi.org/10.1191/030913200701540465

[10] H. C. Tri, L. Hens, P. M. Thien and N. T. Hung, "A Systematic Approach to the Dilemma between Flood Vulnerability and Resilience Review and Concepts," Vietnam Journal of Science and Technology, vol. 55, no. 5, pp. 620636, 2017. DOI: https://doi.org/10.15625/2525$2518 / 55 / 5 / 9195$

[11]C. Béné, R. G. Wood, A. Newsham and M. Davies, Resilience: New utopia or new tyranny? Reflection about the potentials and limits of the concept of resilience in relation to vulnerability reduction programmes, 2012. DOI: https://doi.org/10.1111/j.20400209.2012.00405.x

[12] R. Berman, C. Quinn and J. Paavola, "The role of institutions in the transformation of coping capacity to sustainable adaptive capacity," Environmental Development, vol. 2, pp. 86-100, 2012.

DOI: https://doi.org/10.1016/j.envdev.2012.03.017

[13]N. L. Engle, “Adaptive capacity and its assessment," Global Environmental Change, vol. 21, pp. 647-656, 2011. DOI: https://doi.org/10.1016/j.gloenvcha.2011.01.019

[14]M. Altanbagana and C. Davaanyam, "Assessment of vulnerability of rangeland 
ecosystems," Research on Development of Mongolia, vol. 1, no. 13, pp. 74-85, 2012.

[15]D. Bazargur, Geography of pastoralism, Ulaanbaatar: Institute of Geography of Mongolian Academy of Sciences, 2005.

[16]M. Altanbagana, "Nomadic Pastoralism in Mongolia: Lessons, Transition, Challenges and Sustainability," in Mongols and Mongolia, 2019.

[17] UNICEF, "It is getting hot: Call for Education Systems to respond to the Climate Crisis," UNICEF East Asia and Pacific Regional Office, 2019.

[18]J. Paavola, "Livelihood, vulnerability and adaptation to climate change in Morogoro, Tanzania," Environmental Science and Policy, vol. 11, no. 7, pp. 642-654, 2008. DOI: https://doi.org/10.1016/j.envsci.2008.06.002

[19]H. Eakin, "Institutional Change, Climate Risk, and Rural Vulnerability: Cases from Central Mexico," World Development, vol. 33, no. 11, pp. 1923-1938, 2005. DOI: https://doi.org/10.1016/j.worlddev.2005.06.005

[20]NSO \& World Bank, "The picture of poverty in Mongolia. Based on the results of the household socio-economic survey in 2007-2008," Ulaanbaatar, 2019.

[21]NSO, "Introduction of the Agricultural sector," Ulaanbaatar, 2019.

[22]M. P. Todaro and S. C. Smith, Economic Development, vol. 12, New York: Pearson Education, 2015.

[23] M. Altanbagana, "Identify the Basis and Level of Achievement, Outcomes and Indicators of the Adaptation Activities of the National Contribution to the Implementation of the Paris Agreement," Under the National Capacity Building for Capacity Building (NAP) project, funded by the Climate Green Fund and implemented by the Ministry of Nature, Environment and Tourism and the United Nations Environment Program, Ulaanbaatar, 2021. 